\title{
Sincretismo e produção de sentidos: leitura do pórtico do município de São Miguel das Missões - RS
}

Emili Coimbra de Souza*

Luciana Maria Crestani**

\section{Resumo}

Os pórticos situados à entrada das cidades/municípios, além de darem as boas-vindas aos visitantes, configuram-se como textos - geralmente sincréticos - que carregam em si elementos associados à história da comunidade e, portanto, dizem sobre ela. Entendemos que explorar esse tipo de leitura (não usualmente ensinada nos bancos escolares), além de contribuir para o crescimento cultural do aluno, pode aprimorar competências leitoras, aguçando o olhar e a capacidade de perceber relações entre os elementos do texto e os discursos a eles subjacentes. Tendo isso em conta, o objetivo deste estudo é analisar o pórtico do município de São Miguel das Missões, observando as figuras e os temas que elas recobrem, com intuito de compreender o que esse monumento diz sobre o povo e a comunidade que ele apresenta. A base teórico-metodológica que ancora o estudo é a semiótica discursiva, principalmente os trabalhos de Barros (2001) e Fiorin (2004, 2006, 2016). Também trazemos contribuições de Bakhtin (2003, 2014) no que tange às relações dialógicas implicadas na produção/recepção de enunciados.

Palauras-chave: Ensino de leitura; leitura de pórticos; São Miguel das Missões; semiótica discursiva.

\section{Introdução}

A leitura é uma forma de interação social e, como tal, permite aos indivíduos atuarem no mundo que os cerca e interagirem com seus semelhantes. Ler, então, é condição necessária para as práticas sociais, especialmente numa sociedade letrada. Dessa forma, como professores, é fundamental estarmos conscientes de

\footnotetext{
Doutoranda em Letras no Programa de Pós-Graduação em Letras da Universidade de Passo Fundo, vinculada à linha de pesquisa "Constituição e interpretação do texto e do discurso". Professora no Centro Universitário de União da Vitória - PR. E-mail: prof.emili@uniuv.edu.br

** Doutora em Letras, professora do Curso de Letras e do Programa de Pós-Graduação em Letras da Universidade de Passo Fundo. E-mail: lucianacrestani@upf.br
}

Data de submissão: abr. 2021 - Data de aceite: jul. 2021
http://dx.doi.org/10.5335/rdes.v17i2.12693 
que a leitura deve ser a extensão do espaço escolar na vida do aluno, para que ele seja capaz de entender onde vive e atuar na sociedade onde se insere.

No entanto, nem sempre a leitura recebe a importância que merece no meio escolar, o que se confirma, reiteradamente, a cada ano quando se divulgam os resultados de avaliações oficiais do ensino, a exemplo do Enem. Além disso, dados apontados pelo Indicador Nacional de Alfabetismo (Inaf, 2018) mostram que cerca de um terço da população entre 16 e 65 anos é analfabeta funcional. Para modificar tal cenário, é necessário que no ensino formal se desenvolvam ações efetivamente voltadas à leitura de textos de diferentes naturezas, posto que a interação entre sujeitos não se dá apenas por meio de textos verbais, mas também não verbais e sincréticos. Ler é mais do que compreender palavras escritas, é conseguir perceber sentidos produzidos por diferentes sistemas semióticos, compreendendo os discursos por eles veiculados.

É nesse sentido que se volta nosso interesse em desenvolver um estudo enfocando a leitura de pórticos ${ }^{1}$ situados à entrada das comunidades. Entendemos que esses monumentos são textos - geralmente de natureza sincrética - que dizem sobre a história da comunidade e o dizem, principalmente, por meio da representação figurativa, remetendo o leitor a temas e a discursos atrelados à identidade daquele lugar. Esses textos, entretanto, não costumam ser explorados nas aulas de leitura, tradicionalmente mais voltadas à abordagem do texto verbal. Cremos, porém, que explorá-los pode contribuir para a formação de leitores mais perspicazes, posto que tal prática exige inter-relação entre o que se vê/lê com os (inter)discursos constitutivos do sentido. O objetivo deste trabalho consiste, então, em analisar o pórtico do município de São Miguel das Missões RS, observando as figuras e os temas que elas recobrem, para compreender o que esse monumento diz sobre o povo e a comunidade que ele apresenta.

A escolha por este objeto de análise em específico está associada à riqueza de figuras que compõem o pórtico e ao fato de ele introduzir aos visitantes a história das Ruínas de São Miguel das Missões, local declarado Patrimônio Histórico e Cultural da Humanidade pela UNES$\mathrm{CO}$ e que recebe milhares de visitantes todos os anos, em especial estudantes e professores de diferentes níveis e cursos.

A base teórico-metodológica que dá sustentação a este estudo é a semiótica discursiva, ou semiótica greimaisana, como também é conhecida devido ao seu precursor Algirdas Julien Greimas. A semiótica discursiva é, antes de tudo, uma teoria da significação, que se interessa por textos verbais, não verbais e sincréticos - como é o caso do monumento em análise neste artigo. Ela busca explicar 
como se constroem os sentidos dos textos, concebendo texto como um objeto social e cultural determinado por formações ideológicas específicas (BARROS, 2001), o que significa que ele deve ser analisado também em relação ao contexto sócio-histórico que lhe confere sentido, considerando os interdiscursos que o constituem. Configura-se, também, como uma teoria da relação, posto que é da relação entre os elementos de um texto e deste com outros textos (os interdiscursos) que se constroem sentidos. É nesse viés que propomos a leitura do pórtico à entrada do município de São Miguel das Missões - RS, construído em homenagem ao povo missioneiro.

Este trabalho está organizado em três seções. Na primeira delas, discutimos a concepção de leitura a partir do comportamento humano e das relações construídas com a realidade. Na segunda, apresentamos preceitos da semiótica discursiva que embasam a análise. $\mathrm{Na}$ terceira seção, dedicamo-nos à análise do pórtico.

\section{Leitura: \\ uma prática diária}

Formar leitores poderia ser, resumidamente, o objetivo fundamental para o ensino da leitura. Porém, nos perguntamos: para que ensinamos a ler? Qual o objetivo de aprimorarmos as competências leitoras de nossos alunos?
Cremos que ninguém discordará de que sem a aquisição da leitura o indivíduo fica impossibilitado de avançar etapas na instrução formal e encontra limitações nas práticas de interação em qualquer sociedade letrada. Mas pensar o ensino da leitura voltado a quem "já sabe" ler, com alunos já leitores, pressupõe outro entendimento do que seja ensinar a ler e, assim, nos aproximamos da ideia de favorecer um processo de produção de sentido que permita ao leitor perceber, nos textos, vozes sociais, posições discursivas, estratégias de produção de sentidos, enfim, mecanismos que engendram sentidos mais profundos associados às estratégias manifestas na superfície textual.

Como explica Bakhtin (2014), a leitura é uma complexa atividade cultural que resulta da interação de, no mínimo, dois indivíduos organizados socialmente. O discurso produzido pelo indivíduo é criado para o outro. Portanto, a leitura é social e não individual. É uma atividade de interação social.

Além disso, todo enunciado é gerado da relação do indivíduo com a leitura de diferentes textos ao longo de seu desenvolvimento cultural. Os ouvintes/ leitores produzem novos textos a partir dos enunciados anteriores, que já leram, ouviram, viram (BAKHTIN, 2003). A leitura de um texto, portanto, promove necessariamente um diálogo entre leitor e autor, pressupondo uma resposta ativa 
do leitor. A resposta só será ativa se o leitor dialogar com o texto, o que requer, necessariamente, uma atribuição de sentido ao que lê.

O caráter responsivo é característica intrínseca do enunciado e está associado ao dialogismo, dado o entrecruzamento de discursos que há em cada enunciado. Assim, a compreensão de um texto promove também o diálogo com outros discursos/textos implicados na constituição discursiva daquele. É no texto e pelo texto que vontades discursivas e posições ideológicas se manifestam. Nesse viés, desenvolver competências leitoras implica entender o texto como meio de interação e, ao mesmo tempo, de ação dos homens sobre o mundo e sobre outros homens por meio da linguagem.

Leitura, na perspectiva aqui concebida, não está associada apenas ao código escrito e falado. Quando falamos em competências leitoras, nos referirmos à leitura de textos de diferentes naturezas: os verbais (falados ou escritos); os não verbais - a exemplo das fotografias, das pinturas, das placas de trânsito etc.; e os sincréticos ${ }^{2}$ - como filmes, peças publicitárias, peças de teatro, reportagens etc. A propósito, seja na escola ou fora dela, o sincretismo de linguagens é marcante nos textos que nos rodeiam. Esses textos do cotidiano podem ser artigos de revista ou notícias que relacionem o texto verbal com fotos e/ou infográficos, cartazes afixados em locais públicos, charges, mensagens de WhatsApp, memes, entre tantos outros. Logo, é papel do professor desenvolver competências de leitura condizentes com a contemporaneidade. Nas palavras de Gomes,

O ensino da leitura na escola, entretanto, não pode mais se restringir à linguagem verbal sem comprometer a compreensão global de tão variados e numerosos textos de diversas naturezas e linguagens que nos circundam. Saber interpretar textos não verbais e observar os efeitos de sentido que se produzem a partir da coexistência e interação entre os diversos tipos de linguagem torna-se imprescindível, portanto, para a formação de um leitor competente, capaz de compreender e pensar criticamente os textos e a realidade que o rodeia. (2004, p. 114)

Quanto à compreensão/interpretação do que se lê, Fiorin (2004, p. 113) argumenta que

[...] uma leitura não tem origem na intenção do leitor de interpretar o texto de uma dada maneira, mas está inscrita no texto como virtualidade, como possibilidade. Um texto pode admitir várias interpretações, mas não todas.

No entanto, isso precisa ser ensinado ao aluno, ou seja, é preciso ensinar como se deve olhar para um determinado texto e o que se deve olhar nele para construir os sentidos possíveis. Como bem expõe o autor,

[...] não basta recomendar que o aluno leia atentamente $o$ texto muitas vezes, é preciso mostrar o que se deve observar nele. A sensibilidade não é um dom inato, é algo que se cultiva e se desenvolve (FIORIN, 2016, p. 9). 
Pensar no desenvolvimento de competências leitoras é, portanto, refletir acerca de formas de ver o mundo e de (re) apresentá-lo por meio de diferentes linguagens, considerando as possibilidades de interpretação a partir da observação dos elementos de diferentes naturezas que nos textos se manifestam.

Como sabemos, o leitor não é um sujeito passivo no processo de leitura, ele constrói sentidos no diálogo com o texto. Esses sentidos são decorrentes dos múltiplos discursos que o constituem como sujeito, do que resultam também as diferentes formas de se compreender (ou não) um texto. Como lembra Fiorin (2006), o dialogismo é o princípio de constituição do indivíduo e o seu princípio de ação, uma vez que o conhecimento do leitor constrói-se na interação social, ou seja, na sociedade. É desse modo que o sujeito vai se construindo discursivamente, apreendendo as vozes sociais que constituem a realidade em que está imerso.

Muito embora a compreensão de um texto esteja atrelada aos conhecimentos dos sujeitos, há sempre, como já dissemos, uma vontade discursiva implicada na criação de um enunciado. É essa vontade discursiva que limita o universo de interpretações: não se pode atribuir a um texto sentidos diferentes dos que nele estão inscritos. Isso porque o autor/ enunciador, ao produzir seu enunciado, espalha pistas para que o leitor compreenda o que se quer ali dizer.
Koch (2013) associa a leitura a três metáforas. Na primeira, a metáfora do texto como um mapa da mina, a autora compara o texto aos mapas distribuídos aos escoteiros em explorações pela floresta, os quais contêm marcas, pistas e sinalizações a serem seguidas para que se possa encontrar o local do tesouro, a "mina". Quanto maior a habilidade do escoteiro em segui-las, mais próximo chegará ao lugar onde o tesouro está escondido. Poderíamos dizer que o texto funciona como um GPS feito para conduzir a leitura e dar ao interlocutor a oportunidade de trilhar caminhos conduzidos pelo enunciador. Entretanto, o leitor é livre para tomar seus próprios rumos e nem sempre segue as pistas do GPS, o que favorecerá outras possibilidades de compreensão, dependendo da trajetória percorrida por ele.

A segunda metáfora é a do iceberg. A autora diz que o texto se assemelha a um iceberg, que tem, à flor d'água, uma sequência de elementos linguísticos determinados pela situação comunicativa, pelo gênero textual, pelo contexto sociocultural etc. Abaixo dessa ponta visível do iceberg há, na parte submersa, um enorme conjunto de implícitos, que deverão ser inferidos pelos leitores. A imagem do iceberg ilustra o contato inicial do leitor com apenas a parte visível do texto. Abaixo dela, existem outros elementos textuais submergentes que precisam ser levados em consideração para que o leitor compreenda o que lê. 
A terceira e última metáfora é do texto como hipertexto, segundo a qual para construirmos o sentido de um texto é preciso recorrermos, constantemente, a outros textos, àqueles presentes na situação comunicativa ou no contexto sociocultural em que vivemos. Esses outros textos encontram-se armazenados na nossa memória social e fazem parte do nosso conhecimento de mundo. Há elementos presentes no texto que funcionam como links para nos levar a acessar os saberes necessários à compreensão.

Essas metáforas contribuem para o entendimento do texto como uma unidade de sentido em que interdiscursos e elementos de diferentes níveis estão imbricados. Para explorar, então, a leitura do pórtico, observando os elementos espalhados na superfície e as relações subjacentes que constroem os sentidos desse texto, voltamos nossa atenção, na seção seguinte, às contribuições da semiótica discursiva.

\section{Semiótica discursiva:} aporte teóricometodológico para compreender a construção
de sentidos

Para a semiótica, os textos nascem da união de um plano de conteúdo (da ordem do discurso) com um plano de expressão (da ordem da materialidade textual). Isso significa que um mesmo discurso pode ser manifesto por diferentes planos de expressão: um discurso sobre as mazelas da escravidão, por exemplo, pode ser manifesto por meio de um romance, de um artigo de opinião, de uma pintura, de uma escultura, de uma peça teatral, de um filme etc. É assim que a semiótica se volta ao estudo da significação abarcando textos verbais, não verbais e sincréticos. Um texto é, como explica Barros (2001), um objeto de significação e, ao mesmo tempo, de comunicação entre sujeitos. O pórtico, objeto de análise, é concebido como um texto sincrético, posto que o conteúdo é manifesto por linguagens verbal e não verbal.

Greimas e Courtés (2012, p. 467) consideram "sincréticas as semióticas que - tal como a ópera ou o cinema - empregam várias linguagens de manifestação". Teixeira (2003, p. 14) complementa o sentido de sincretismo ao explicar que,

Objetos sincréticos, para dizer com mais rigor, são aqueles em que o plano de expressão se caracteriza por uma pluralidade de substâncias mobilizadas por uma única enunciação cuja competência de textualizar supõe o domínio de várias linguagens para a formalização de uma outra que as organize num todo de significação.

A análise de textos dessa natureza requer um olhar atento tanto a elementos do plano do conteúdo quanto do plano da expressão, posto que ambos produzem significações. Na sequência, 
apresentamos pressupostos teóricos que dão suporte à análise desses planos.

\section{O plano de conteúdo e o percurso gerativo do sentido}

O plano de conteúdo é dividido em três níveis através dos quais se depreende uma organização que forma o chamado percurso gerativo de sentido. Este é

[...] uma sucessão de patamares, cada um dos quais suscetível de receber uma descrição adequada, que mostra como se produz e se interpreta o sentido, num processo que vai do mais simples ao mais complexo (FIORIN, 2016, p. 20).

Os três níveis do plano de conteúdo são o fundamental, o narrativo e o discursivo.

O nivel fundamental de um texto é concebido por dois termos contrários pertencentes a uma mesma categoria semântica, como vida versus morte, natureza versus cultura etc. Esses termos opostos são dotadas de um valor - um deles será valorado positivamente e o outro negativamente no texto. No entanto, não é o leitor quem define a valoração desses termos, ela vem inscrita na posição discursiva que o texto sustenta. Por exemplo: um texto pode valorar positivamente e vida e negativamente a morte. Em outros casos, a morte pode ser valorada positivamente e a vida, negativamente. Exemplo disso é o discurso de um doente terminal para o qual a morte seria a forma de cessar o sofrimento. Os termos contrários remetem às relações dialógicas constitutivas dos enunciados: ao se valorar positivamente a vida, nega-se a morte, ou vice-versa, dialogando com outros discursos que também abordam tais temas.

No segundo nível, denominado narrativo, o texto passa a ser organizado do ponto de vista de um sujeito e da relação deste com um objeto de valor. Nesse nível, busca-se observar se o sujeito está de posse ou privado do objeto valor que deseja e se efetua transformações no sentido de alcançá-lo. No dizer de Barros (2001), o nível narrativo constitui um simulacro das ações dos homens sobre o mundo e sobre os outros homens na busca por valores que desejam. Grosso modo, os textos retratam as buscas, as disputas, as transformações operadas pelos sujeitos na sociedade em busca de seus desejos.

No terceiro e último nível, denominado discursivo, os percursos narrativos se tornam estruturas discursivas assumidas pelo sujeito da enunciação (FIORIN, 2016), ou seja, é quando o sujeito da enunciação faz escolhas temáticas e figurativas para recobrir as estruturas narrativas. O nível discursivo é o mais complexo e concreto, assim como o mais próximo da manifestação textual. Pela análise das figuras e dos temas que elas recobrem podemos ler o pórtico e compreender-lhe sentidos mais profundos. É, pois, necessário explicar o que são temas e figuras. 
Os temas são os conteúdos semânticos tratados de forma abstrata, e as figuras, o investimento semântico-sensorial dos temas. Os temas (abstratos) e as figuras (concretos) são determinados sócio-historicamente e trazem para os discursos o modo de ver e de pensar dos sujeitos sociais inseridos num determinado contexto sócio-histórico. Ou seja, a escolha de determinados temas e figuras revelam a estratégia adotada para, no contraponto com a ação interpretativa, reiterar a construção social do sujeito.

Segundo Fiorin (2016, p. 91) "temas são categorias que organizam, categorizam, ordenam os elementos do mundo natural". A tematização expressa elementos abstratos buscando explicar a realidade e representar o mundo mediante conceitos.

As figuras correspondem aos elementos que remetem ao mundo natural. Os elementos figurativos

[...] criam um efeito de realidade, pois constroem um simulacro da realidade, representando, dessa forma, o mundo; [eles] têm uma função descritiva ou representativa [...] são feitos para simular o mundo" (FIORN, 2016, p. 91).

Num filme, por exemplo, para recobrir o tema da riqueza, podem ser associadas ao sujeito figuras como: uma casa luxuosa com muitos cômodos, vários empregados, automóveis luxuosos, roupas de grife etc. A depender do plano de expressão do texto, as figuras podem ser descritas verbalmente - como num livro - ou materializadas de forma icônica, como num filme.

Como explica Fiorin (2016), para achar o tema que dá sentido às figuras é preciso observar os encadeamentos das figuras e dos temas, ou seja, os percursos figurativos e temáticos. A esse encadeamento de temas e figuras dá-se o nome de isotopia. Então, para dizer que um texto fala sobre um determinado tema, é preciso observar nele marcas recorrentes que possibilitem afirmar isso. A reiteração de traços temáticos e/ou figurativos garante a coerência do texto e possibilita compreender os sentidos deste.

Na leitura de monumentos, como é o caso do pórtico, a compreensão das figuras que o constituem está relacionada a interdiscursos que precisam ser recuperados, encaminhando o sujeito-leitor a outras percepções que extrapolam o nível superficial do texto.

\section{O plano de expressão e a produção de sentidos}

O plano de expressão, como já mencionamos, diz respeito ao modo de materialização do texto, ou seja, às diferentes linguagens por meio das quais um discurso pode se manifestar. No texto verbal, as figuras e temas são apresentados por palavras. No texto visual, apresentam-se visualmente. Por exemplo, num livro, a descrição das figuras associadas a um cer- 
to espaço se dá por meio de palavras; num filme, são os objetos que vão representar tal espaço, figurativizando o tema do conforto, da sofisticação, da vida no campo ou na cidade e assim por diante. Assim, todos os elementos figurativos associados a um determinado sujeito são importantes para compreensão dos temas a ele associados.

Segundo Teixeira (2009), a leitura/ análise do plano de expressão deve começar pelo mais simples e aparente, com observação e descrição minuciosa. Em seguida, passar à identificação da estratégia metodológica mais eficiente para definir as categorias e o exame dos procedimentos. A autora propõe uma metodologia de análise de textos sincréticos que leva em conta as categorias da expressão plástica propostas por Floch (1985). Segundo ela, a análise requer que se observem os seguintes elementos:

1. Figuras e temas disseminados no discurso por meio de elementos verbais e visuais

[...]; 2. Categorias cromáticas, eidéticas e topológicas do plano da expressão plástica

[...]; 3. Mecanismos de articulação entre plano de conteúdo e plano da expressão;

4. Formas de incidência das categorias tensivas no percurso para imprimir ritmo ao texto;

5. Estratégia enunciativa que organiza todos os elementos e estabelece formas de interação entre enunciador e enunciatário. (TEIXEIRA, 2009, p. 61)

Desses aspectos elencados, importam-nos, neste trabalho, os dois primeiros e o último. A categoria cromática diz respeito às cores e à luminosidade, observáveis por meio de oposições como brilhante/ opaco, puro/mesclado, claro/escuro etc. A categoria eidética engloba as formas, as combinações de linhas e volumes, como curvilíneo/retilíneo, verticalidade/horizontalidade, grande/pequeno. Já a categoria topológica diz respeito à disposição das formas/elementos no espaço, a saber, central/periférico, esquerdo/direito, frente/trás. Há ainda a categoria matérica, que engloba oposições como liso/rugoso, leve/pesado, macio/duro. Essas categorias produzem diferentes efeitos de sentido no texto, implicando na significação.

A partir das considerações de Teixeira (2009), podemos afirmar que o plano de expressão de qualquer texto verbovisual/ sincrético pode ser analisado como manifestação visual num suporte planar, observando-se categorias cromáticas, eidéticas, topológicas, matéricas. As próprias figuras, num texto visual, materializam-se por meio dessas categorias.

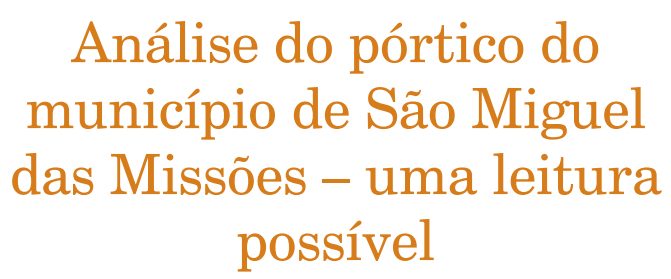

Situados à entrada das cidades ou dos municípios, os pórticos têm como objetivo identificar a comunidade aos visitantes e recepcioná-los de forma acolhedora. No entanto, a maioria dos pórticos não se restringe a essas informações. Em geral eles apresentam, de modo figura- 
tivo, aspectos importantes relacionados à identidade, aos costumes, à história daquele município. Quando remetem a fatos históricos, perpetuam tal acontecimento e ratificam a importância dele para a comunidade. É esse o caso do pórtico situado à entrada do município de São Miguel das Missões.

A vila de São Miguel das Missões surgiu no ano de 1926, momento em que foi efetuado um loteamento urbano em torno dos remanescentes do antigo povo jesuítico-guarani. Em 29 de abril de 1988, a vila de São Miguel emancipou-se de Santo Ângelo, por meio de plebiscito, criando-se assim o Município de São Miguel das Missões.

O município está situado na região Noroeste do estado do Rio Grande do Sul - Brasil e abriga o Sítio Arqueológico de São Miguel Arcanjo, popularmente conhecido como Ruínas de São Miguel das Missões, conjunto de remanescentes da antiga redução jesuítica de São Miguel Arcanjo, integrante dos chamados Sete Povos das Missões ${ }^{3}$. As Ruínas de São Miguel das Missões foram declaradas Patrimônio Histórico e Cultural da Humanidade pela Organização das Nações Unidas para a Educação, a Ciência e a Cultura (UNESCO), em 1983. É um local que recebe milhares de visitantes todos os anos, inclusive grupos de estudantes de diferentes níveis que buscam na visitação um modo de conhecer e - em alguma medida - de vivenciar a história associada às raízes do povo missioneiro.
Como ponto de partida para análise, tomamos a imagem do pórtico na sua totalidade e descrevemos os elementos que o compõem. Na sequência, observamos as figuras de forma individualizada, explorando os temas que elas recobrem a partir de interdiscursos históricos a elas associadas. Também exploramos categorias da semiótica plástica que produzem significados relevantes. Ao final, retomamos o pórtico como um todo, explicando o que esse texto nos diz. Assim, passamos das estruturas mais aparentes e concretas às mais profundas e abstratas.

Figura 1 - Pórtico do Município de São Miguel das Missões - RS

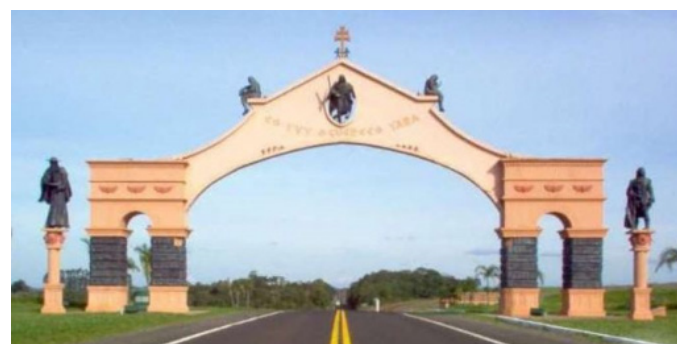

Fonte: (PORTAL DAS MISSÕES, 2018).

O Pórtico de São Miguel das Missões (Figura 1), situado na RS 536, a 16 km da sede do município, é um monumento em homenagem aos missioneiros ${ }^{4}$, como o próprio nome da cidade já permite inferir. Foi construído em concreto armado e detalhes em blocos de arenito, as esculturas que o compõem são de bronze, assim como os painéis que revestem os pilares de sustentação. 
À extrema esquerda, sobre um pedestal um pouco à frente do portal, está a escultura de um padre, o que é possível inferir pelos detalhes da roupa e pelo símbolo que a imagem carrega numa das mãos. À extrema direita, outro pedestal à frente do pórtico eleva a escultura de um índio guerreiro, como acusam a veste que usa, a espada em punho, os cabelos compridos e traços de suas feições. Essas duas esculturas posicionadas um pouco à frente do portal de entrada são, respectivamente, o padre jesuíta Cristóvão de Mendonza e o cacique guarani Sepé Tiaraju, sujeitos que marcaram a história do lugar, como se verá adiante.

Atrás dos pedestais, duas torres cada uma formada por duas colunas sustentam o portal que perpassa de lado a lado a rodovia. Nas colunas das torres, painéis esculpidos em bronze retratam atividades desenvolvidas pelo povo que habitava aquela região. No enquadramento central superior do portal, novas esculturas chamam atenção: à esquerda, um índio sentado segurando um livro; ao centro, no topo, uma cruz abraçada por dois anjos; abaixo da cruz, num vão oval, a escultura de um sujeito empunhando uma espada que, como veremos, trata-se de São Miguel Arcanjo; e, à direita, a de uma índia segurando ao colo uma criança que aponta para o céu. Na base do enquadramento, em fomato côncavo, está gravada a frase Co Yvy Oguereco Yara"Esta terra tem dono", em língua guarni.
À primeira vista, notamos que o formato do Pórtico (categoria eidética) remete ao da Igreja das Ruínas de São Miguel das Missões (Figura 2), tecendo com ela uma relação intertextual. Isso indica que a leitura do pórtico precisa recuperar os interdiscursos históricos associados às Ruínas de São Miguel das Missões. A Igreja foi construída com pedra de arenito, branqueada com argila clara chamada tabatinga, fazendo com que suas paredes fossem mais espessas. Foi construída no período final da arquitetura barroca e a influência desse estilo está presente nas torres quadradas com aberturas côncavas, assim como nas ondulações côncavas da fachada (PORTAL DAS MISSÕES, 2018). As linhas barrocas e as pedras de arenito também estão presentes no pórtico, assim como as cores mais claras e mais escuras que produzem a sensação de luz e sombra. Observe-se que o portal que perpassa a rodovia tem uma coloração mais clara do que a das torres que o sustentam (Figura 3).

Figura 2 - Ruínas da Igreja de São Miguel das Missões

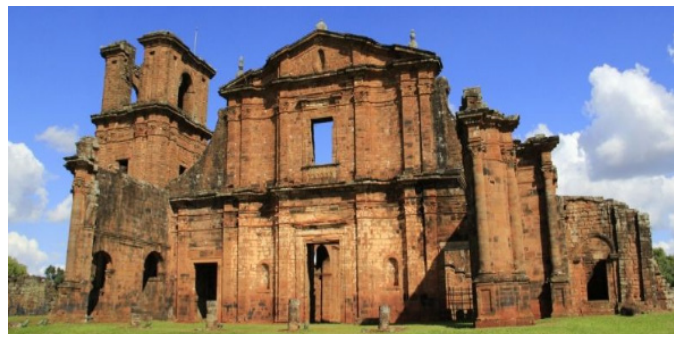

Fonte: (PORTAL DAS MISSÕES, 2018) 
Figura 3 - Pórtico de São Miguel das Missões

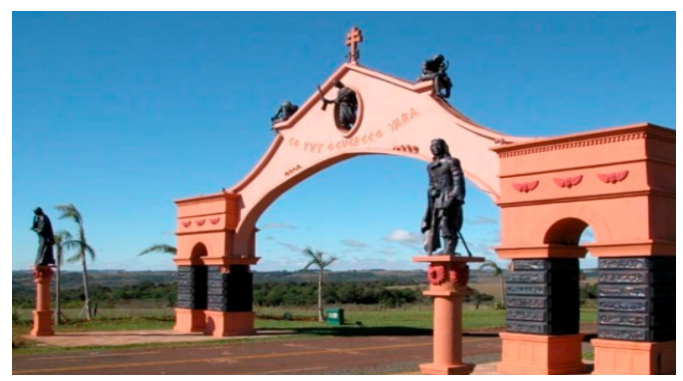

Fonte: (DAS AUTORAS, 2018)

Nas duas torres do pórtico - que remetem às torres da Igreja - encontramos placas em bronze esculpidas em baixo relevo (Figura 4). Essas placas retratam aspectos da vida em comunidade dos guarani, assim como as batalhas travadas com os colonizadores e a morte de Sepé Tiaraju - o índio herói - na Batalha de Caiboaté 5 .

Figura 4 - Placas esculpidas nos pilares

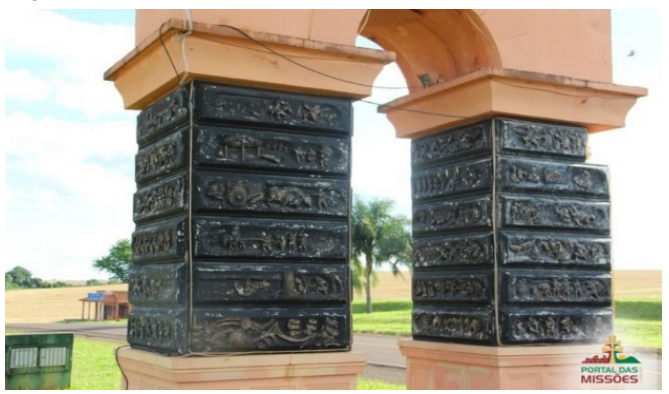

Fonte: (PORTAL DAS MISSÕES, 2018)

As placas mostram atividades diárias realizadas na redução, como a coleta de alimento, a pescaria e o cultivo da terra (ensinamento aperfeiçoado pelos jesuítas). Remetem ao modo como a alimentação indígena era preparada, à organização do sistema de moradia, às festividades, à maneira como a orientação espiritual dos índios era desenvolvida, além do aprendizado da música, que servia de catequese para os aprendizes da fé. Os registros encontrados nos pilares, portanto, lembram a evolução da nação guarani e sua trajetória enquanto grupo social, retratando um cotidiano dividido entre dias de calmarias e de lutas. As placas indicam, fundamentalmente, a relevância do povo guarani e suas contribuições para a cultura regional, apresentando a organização da sociedade local da época.

Tomemos o enquadramento central ao alto do pórtico (Figura 5):

Figura 5 - Elementos enquadrados ao alto do pórtico

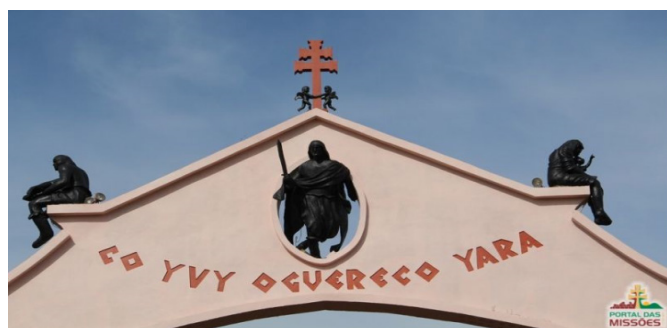

Fonte: (PORTAL DAS MISSÕES, 2018)

Para fins de organização, começamos a leitura pelas extremidades e vamos em direção aos elementos centrais. À esquerda, temos a imagem de um índio sentado, olhar distante, com o braço direito apoiado na perna direita e, na mão esquerda, um livro aberto (Figura 6). 
Figura 6 - Índio sentado com livro na mão

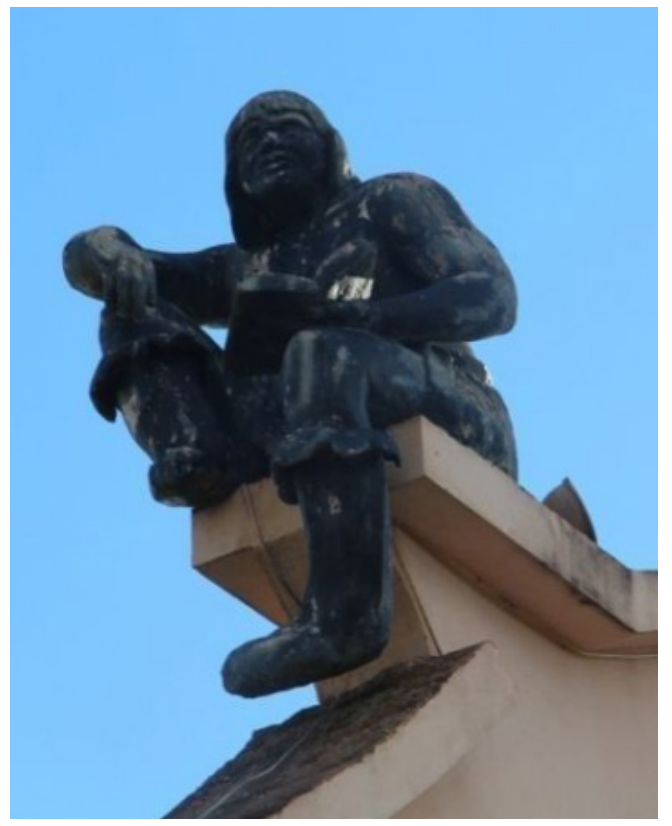

Fonte: (PORTAL DAS MISSÕES, 2018)

Há elementos na escultura que permitem identificar tal imagem como sendo um índio: cabelos lisos com franja e não muito curtos, costume dos guaranis na época; o uso de saiote, vestuário indígena que servia para cobrir o sexo no período da colonização; o físico delineado também remete às características de um povo cujo cotidiano era de trabalho e lutas, fatores que auxiliavam na constituição de tais traços.

Na mão esquerda, o indígena segura um livro aberto. Podemos conceber tal livro como sendo uma Bíblia, remetendo à catequização e ao papel de civilizadores dos jesuítas da Companhia de Jesus que atuavam na região; ou, num sentido metafórico, o "livro aberto" pode indicar a perpetuação dos fatos históricos ali ocorridos que, registrados, não se perdem no tempo e se dão a conhecer às gerações futuras. $\mathrm{O}$ olhar do índio se direciona à cidade em que se localizam as Ruínas de São Miguel, local onde viveu a comunidade indígena e onde ocorreu a Guerra Guaranítica (1753-1756), que dizimou mais de vinte mil índios guaranis da região. A expressão facial do índio é de desolação, indicando o pesar pelos fatos ocorridos na comunidade que ele representa.

À direita da Cruz Missioneira, projeta-se a escultura de uma índia com uma criança no colo (Figura 7).

\section{Figura 7 - Índia com criança ao colo}

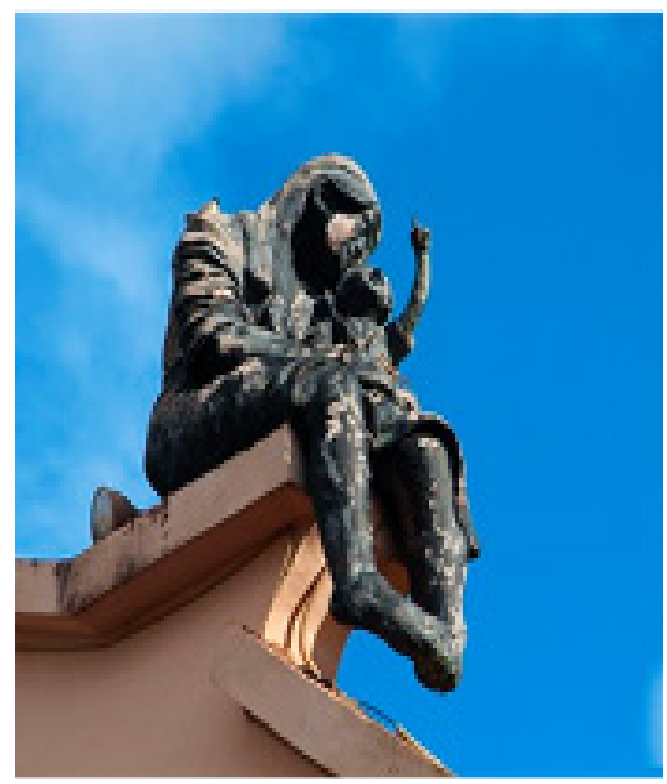

Fonte: (PORTAL DAS MISSÕES, 2018) 
Os traços que possibilitam concebê-la como membro da nação indígena que ali habitava são os cabelos longos e lisos, os pés descalços (na época era comum os índios não usarem calçados, pois esse hábito não fazia parte de sua cultura) e também pelo fato de que as mulheres eram as responsáveis por cuidar dos filhos enquanto os homens dedicavam-se aos trabalhos de cultivo da terra e participavam de lutas constantemente. As figuras ali projetadas parecem ser de mãe e filho, dada a forma como se projeta a imagem da mulher em direção à criança, bem como sua expressão facial, indicando cuidado e afeto. $\mathrm{O}$ braço da criança elevado e com a mão apontado ao céu remete à crença dos indígenas em uma entidade divina, herança da catequização jesuítica.

Disposta no ponto mais alto do pórtico, abraçada por dois anjos, aparece a Cruz Missioneira (Figura 8).

Figura 8 - Cruz Missioneira

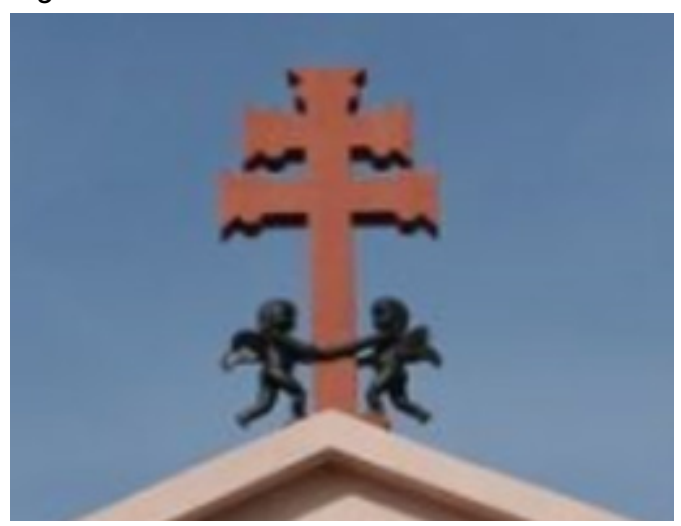

Fonte: (PORTAL DAS MISSÕES, 2018)
Segundo informações do site Portal das Missões (2018), a Cruz Missioneira foi trazida pelos padres jesuítas da Companhia de Jesus, cujos membros eram, em sua maioria, de origem espanhola da cidade de Caravaca de La Cruz, sendo adotada como símbolo de conquista de território. Ela foi adotada pelos índios nas Missões em todo o território do Rio Grande do Sul, como símbolo do bem contra o mal. Os dois braços simbolizam a fé redobrada, foco, abnegação. A Cruz é considerada como um amuleto, uma proteção espiritual contra todos os males.

Quanto à presença das figuras de anjos "abraçando" a Cruz, podemos associá-la à lenda mitológica da Cruz de Caravaca. Essa lenda conta que na região onde hoje é a Espanha, quando dominada pelos povos mouros, no século XIII, um rei mouro manteve em cativeiro padres. Numa ocasião, o rei obrigou um sacerdote prisioneiro a celebrar uma missa. $\mathrm{O}$ vigário, no momento de celebração, parou com os ritos sacros e disse que não conseguia rezar ou responder as inquietações do rei Abu Zeid, explicou que não poderia prosseguir porque lhe faltava a Santa Cruz, símbolo maior da fé cristã. $\mathrm{O}$ rei esbravejou e o sacerdote se ajoelhou quieto enquanto os guardas e convidados o ofendiam, esperando a ordem do rei para executá-lo. Naquele momento, o teto se abriu em luz e dois anjos desceram do céu trazendo a Cruz de Quatro Braços. Diante do milagre, o 
rei Abu Zeid converteu-se ao cristianismo (ORIGEM..., 2018).

Logo embaixo da Cruz Missioneira, está a escultura de São Miguel Arcanjo (Figura 9), representado pelo manto, pelas asas e pela espada que empunha na mão direita.

Figura 9 - São Miguel Arcanjo

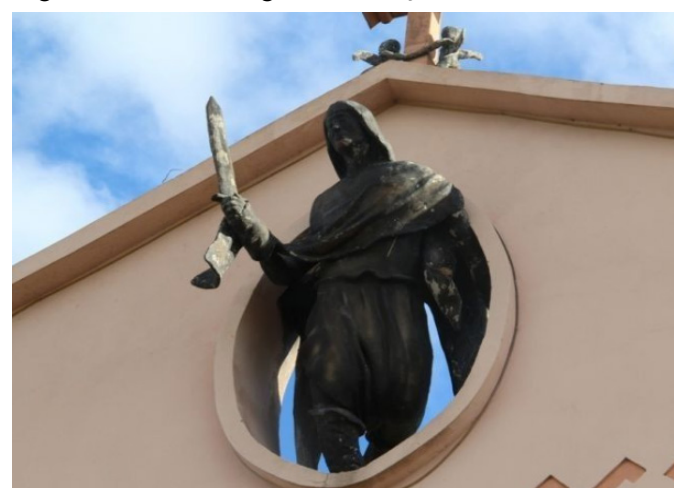

Fonte: (PORTAL DAS MISSÕES, 2018)

São Miguel Arcanjo é considerado, na religião católica, o guardião celeste, príncipe e guerreiro que defende o trono celestial. É também reconhecido como o defensor e protetor do Povo de Deus, Padroeiro da Igreja Católica, chefe supremo do exército celestial, dos anjos fiéis a Deus, o Arcanjo da Justiça e do arrependimento, grande combatente e vencedor das forças do mal. (HISTÓRIA..., s/d). Essa leitura do anjo guardião guerreiro é reiterada no pórtico.

As figuras de São Miguel Arcanjo, da Cruz Missioneira e dos anjos recobrem o tema da religião e destacam a influên- cia desta na história da comunidade. A disposição topológica dessas figuras centralizadas no ponto mais elevado do portal - marcam a representatividade e a importância da religião cristã na formação da comunidade. Tanto é que lhe atribuem o nome: São Miguel das Missões. As esculturas dos representantes do povo guarani estão nas extremidades, enquanto as figuras religiosas ocupam o lugar de destaque. Essa disposição é significativa, permitindo inferir pelo viés de quem a história foi contada e a quem se atribuem as forças atuantes.

$\mathrm{Na}$ extermidade inferior do pórtico, em formato abaulado, identificamos frase em guarani - Co Yvy Oguereco Yara. Ela significa "Esta terra tem dono", reproduzindo a fala do índio guerreiro, herói e mártir, Sepé Tiaraju. Representa a resistência indígena quando das investidas dos colonizadores na tomada de seus territórios. A frase está em destaque, demostrando a valentia e a força de defesa da terra, do espaço, das famílias, da cultura, das tradições do povo indígena. Foi proferida na Batalha de Caiboaté, confronto no qual Sepé foi morto (PORTAL DAS MISSÕES, 2018).

À frente do pórtico, elevados sobre pedestais, aparecem as esculturas do Padre Cristóvão de Mendonza (Figuras 10 e 11) e de Sepé Tiaraju (Imagem 12). O padre aparece no lado esquerdo do pórtico e o índio, no direito. 
Figuras 10 e 11 - Padre Cristóvão de Mendonza
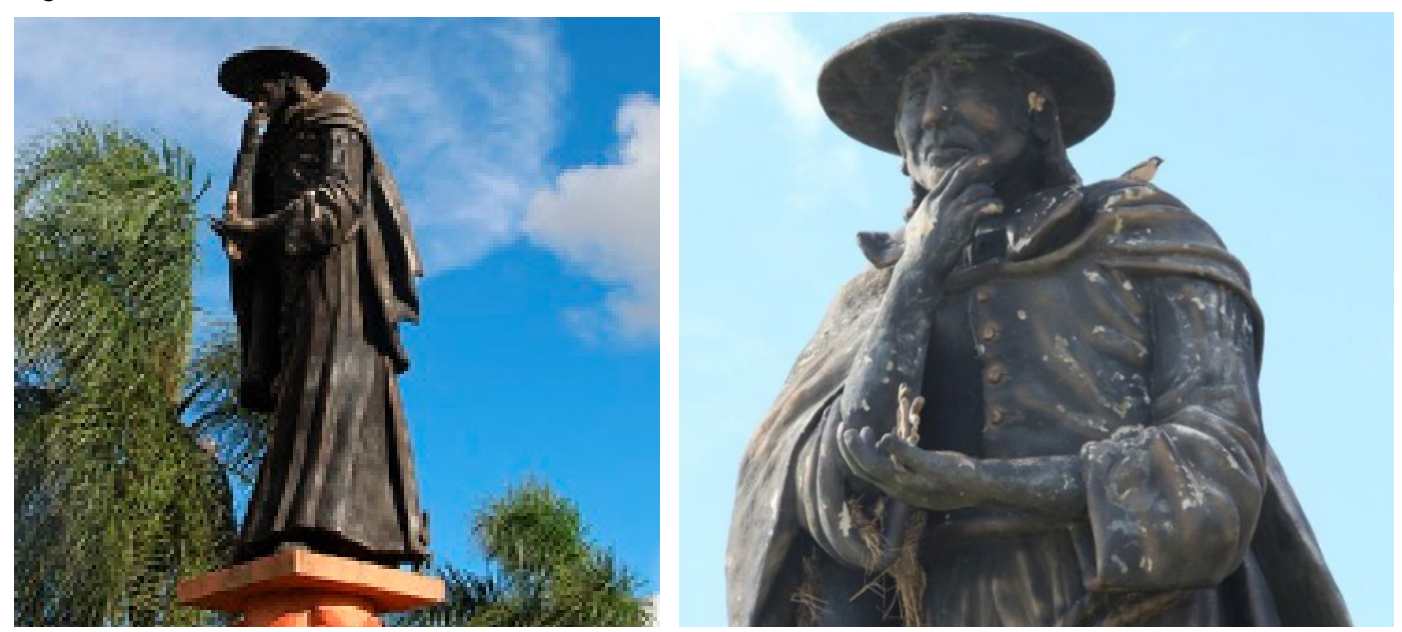

Fonte: (PORTAL DAS MISSÕES, 2018)

Figura 12 - Sepé Tiaraju

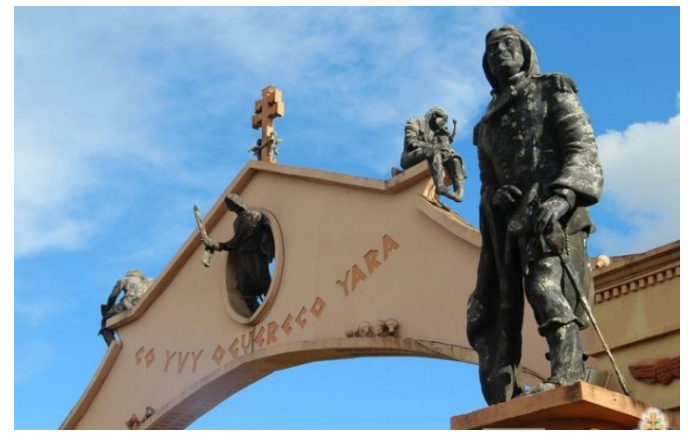

Fonte: (PORTAL DAS MISSÕES, 2018)

O Padre Cristóvão de Mendonza era membro da Companhia de Jesus e foi o fundador da Redução de São Miguel Arcanjo $^{6}$. O Padre é representado com vestes características dos colonizadores (capa e chapéu) e dos padres jesuítas (batina), o que remete à dupla missão dos religiosos espanhóis: conquistar ter- ritórios (idealizar e construir as missões compostas por sete reduções) e catequizar os povos nativos ${ }^{7}$. A imagem retrata o padre como se estivese caminhando, dado o movimento insinuado pela capa. A mão direita elevada ao queixo imprime-lhe um aspecto pensativo, como alguém preocupado com que se passava naquele lugar. Na mão esquerda, Cristóvão de Mendonza carrega algo que se assemelha ao monograma JHS, transcrição do nome abreviado de Jesus em grego, Inooús (em maiúsculas, $\mathrm{IH} \Sigma \mathrm{OY} \Sigma$ ), estabelecendo uma relação direta com a Igreja Católica (Imagem 13). 
Imagem 13 - Símbolo da Igreja Católica

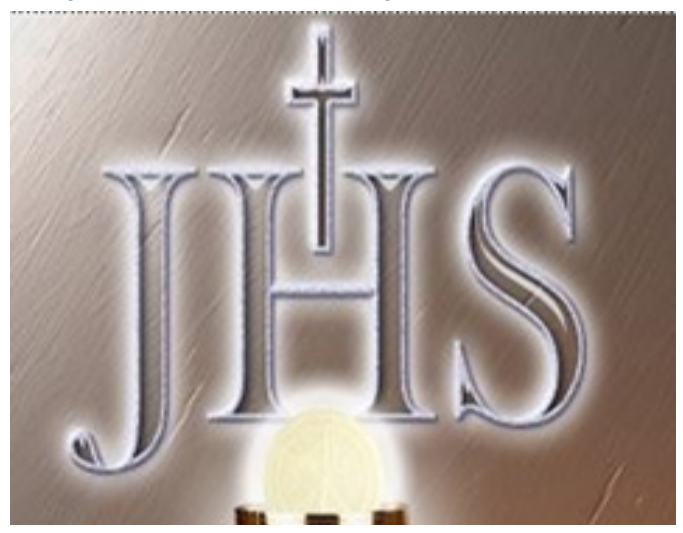

Fonte: (BIANCHINI, 2019)

O "J" corresponde à pronúncia do "I" na antiguidade, assim como o "V" era empregado como "U”. A interpretação aceita é a abreviação da frase em latim: "Iesus Hominum Salvator" (Jesus Salvador dos Homens). Esse monograma, de origem cristã, foi criado por São Bernardino de Sena, no século XV, e adotado por Santo Inácio de Loyola, no século XVI, como emblema da Companhia de Jesus (ALETEIA, 2017). Podemos então dizer que o Padre Cristóvão de Mendonza está a mostrar a presença, naquele local, da fé cristã entre os índios guarani.

Sepé Tiaraju, tal qual o Padre Cristóvão de Mendonza, é apresentado como figura de destaque, elevado num pedestal à direita e à frente do pórtico. $\mathrm{O}$ índio é retratado de forma imponente, com olhar atento e espada na cintura, projetando a ideia de valentia atribuída ao cacique guarani que se tornou líder das milícias indígenas nas batalhas contra as tropas luso-brasileira e espanhola na Guerra Guaranítica. $\mathrm{O}$ índio guerreiro morreu durante combate contra o exército espanhol na batalha de Caiboaté, na entrada da cidade de São Gabriel, durante a invasão inimiga às aldeias dos Sete Povos.

Sepé Tiaraju foi criado pelos padres jesuítas, pois seus pais morreram em uma epidemia de escarlatina. Aos poucos, foi adquirindo o conhecimento e a cultura dos jesuítas, o que se somaria ao espírito de liberdade guarani, o suficiente para transformá-lo em um dos maiores líderes da liberdade guarani. Foi cacique indígena de São Miguel das Missões e tornou-se uma figura lendária e ambígua, sendo tratado como santo popular para alguns, símbolo de bravura do caudilhismo gaúcho ou representação de resistência dos oprimidos, por outros. (SEPÉ TIARAJU, 2019). O índio guerreiro foi inscrito no Livro dos Heróis da Pátria, em 2009.

Tendo em conta a categoria topológica, as duas imagens alocadas em pedestais à frente do pórtico já indicam a importância desses sujeitos para a comunidade que apresentam. Mesmo que o leitor nada saiba sobre o padre ou sobre o índio ali figurativizados, as imagens de ambos em pedestais, cada um de um lado da rodovia, permitem inferir que a história daquele lugar está associada aos feitos desses sujeitos, os quais também representam, de forma metonímica, os grupos sociais que ali residiam. Há que se considerar que a 
escultura de Sepé Tiaraju está situada no lado direito da entrada do pórtico, o que lhe atribui maior destaque que a figura do Padre Cristóvão de Mendonza, situada à esquerda. Tal aspecto indica a importância do cacique para o seu povo e para o povo missioneiro.

Ao olharmos para a totalidade do texto, percebemos que as figuras do pórtico recobrem temas associados à trajetória da conquista do território missioneiro pelos espanhóis, à catequização dos índios pelos padres jesuítas, à rotina do povo guarani em dias de calmaria e de batalhas. Estão ali representadas figuras marcantes que contam sobre o local, remetendo o leitor à retomada de discursos históricos.

A frase destacada no alto do pórtico soa até hoje como um aviso: "Esta terra tem dono". As figuras do pórtico - inclusive o formato arquitônico deste - contam a história do local, indicando os sujeitos que ali residiam, as suas crenças, os seus modos de vida, os seus valores, a sua identidade, e as lutas que travaram naquela e por aquela terra. Assim, o pórtico também permite recuperar as ações e transformações ocorridas naquela comunidade, revelando um percurso que modificou $o$ modo de vida dos indígenas, seifou milhares de vidas e produziu heróis. Denota, ainda, o papel de destaque atribuído à religião - e aos seus representantes - nesse itinerário. Acrescente-se a isso o fato de o nome da cidade ser também de cunho religioso. Sim, o pórtico retrata a saga guarani, mas dá destaque às forças religiosas que ali atuaram. Isso aponta, em alguma medida, o poder simbólico atribuído aos representantes de um e de outro universo social.

Num nível mais profundo de leitura, então, podemos dizer que esse texto se constrói sobre a categoria de base vida versus morte, associada à liberdade versus submissão e à posse versus privação. A luta pela posse/manutenção do território, que se configura também como luta pela liberdade, reafirma-se nas figuras dos sujeitos empunhando espadas e no dizer inscrito em guarani, representando a bravura, a coragem de um povo que não se deixa dominar.

O pórtico, com seu caráter imponente, é um texto sobre as raízes da comunidade local. Remete a acontecimentos históricos que podem ser reconhecidos por todos como forma de promover e valorizar a memória social do lugar. Como monumento, o Pórtico de São Miguel das Missões eterniza figuras históricas e seus feitos, impedindo que discursos constitutivos da identidade daquele povo caiam no esquecimento.

\section{Considerações finais}

Como afirma Greimas (1975), o sentido dos objetos não está somente no que eles querem dizer no plano da expressão, mas no que observamos e interpretamos no plano do conteúdo. Assim, para a 
compreensão da significação existente no pórtico analisado é preciso ler as figuras, associá-las a temas e recuperar (inter) discursos. É preciso observar, também, cores, formas e disposição dos elementos no espaço, uma vez que esses aspectos também significam. Este pórtico é um texto sincrético cujo significado transcende a simples aparência. $\mathrm{O}$ sentido desse texto não se constrói à primeira vista - até mesmo pela sua natureza estética - mas no diálogo com outros discursos que ele suscita. Para compreendê-lo, é preciso aguçar o olhar e revisitar a história. A isso está associada também a importância de explorar textos dessa natureza, posto que ensinar a ler é ensinar a ver além da aparência, a tecer relações discursivas que permitam (re)construir sentidos.

A leitura, quando desenvolvida com um olhar que envolve demandas históricas, sociais e ideológicas, possibilita uma maior interação e atuação do sujeito-leitor, pois instiga-o ao exercício de uma leitura significativa, dando condições para que atribua sentidos ao que lê, contribuindo para o desenvolvimento social desses sujeitos. Nesse viés, destacamos as contribuições da semiótica discursiva para o trabalho com textos, posto que ela se configura como um guia ao olhar, indicando o que se pode olhar e como se pode olhar para um texto para compreender sentidos nele implicados. Tal abordagem permite, ainda, compreender o texto como produto de concepções ideológicas e de "recortes culturais" - sustentando sistemas de valores - que se apresentam nas situações de comunicação por meio de diferentes linguagens.

Esperamos que a análise ora feita possa contribuir, em alguma medida, para aguçar o olhar de professores e estudantes, dialogando com outras propostas que, assim como esta, preocupam-se com o ensino da leitura.

\section{Syncretism and production of meanings: reading the portico of the municipality of São Miguel das Missões - RS}

\section{Abstract}

The porticos situated at the entrance of cities/municipalities, despite of welcoming the visitors, are set up like texts - usually syncretic - which bring themselves elements associated to the history of the community and, therefore, say something about it. We understand that exploring this kind of reading (not usually tought in schools) beyond contributing to the student's cultural growth, can develop reading competences, improving the view and the ability to perceive the relation between the text elements and the underlying discourses. Taking it into account, the aim of this study is to analyse the portico of the municipality of São Miguel das Missões, observing the figures and the topics covered by them, intending to comprehend what this monument says about the people and community presented. The theoretical-methodological basis that gives support to this study is the dis- 
cursive semiotics, mainly the studies by Barros (2001); Fiorin (2004, 2006, 2016). There are also contributions by Bakhtin (2003, 2014), referring to the dialogic relations applied to production/reception of the statements.

Keywords: Reading teaching; reading of porticos; São Miguel das Missões; discursive semiotics

\section{Notas}

1 Segundo o Dicionário Michaelis (2019) o vocábulo pórtico tem origem na palavra latina portǐcus, que significa alpendre, galeria sustentada por colunas. Ainda, quanto à sua definição, o dicionário nos apresenta como sendo um átrio espaçoso, com abóboda sustentada por colunas ou pilares, portal.

2 Textos sincréticos são constituídos por diferentes linguagens. Um filme, por exemplo, é constituído por linguagem verbal, visual e sonora. Voltaremos a esse conceito na seção sobre a semiótica discursiva.

3 Nome dado ao conjunto de sete aldeamentos indígenas fundados pelos jesuítas espanhóis no Rio Grande do Sul. Era composto pelas reduções de São Francisco de Borja, São Nicolau, São Miguel Arcanjo, São Lourenço Mártir, São João Batista, São Luiz Gonzaga e Santo Ângelo Custódio. (FONSECA, 2011)

4 As missões jesuítico-guarani foram parte do projeto de colonização da coroa espanhola no entorno dos rios Uruguai e Paraná nos séculos XVII e XVIII e que compreende hoje territórios do Rio Grande do Sul, Paraná, Argentina, Uruguai e Paraguai.

5 Segundo Martinelli et al (2017), após o ano de 1750, com a assinatura do "Tratado de Madri", ocorreu a troca da Colônia de Sacramento (possessão portuguesa em meio ao território espanhol), pelos Sete Povos das Missões (São Francisco de Borja, São Nicolau, São Miguel Arcanjo, São Lourenço Mártir, São João Batista, São Luiz Gonzaga e Santo Ângelo Custódio). O Tratado determinava que os índios missioneiros deveriam abandonar suas reduções, podendo levar seu gado, o produto de suas lavouras e outros bens, evitando, assim, possíveis revoltas dos indígenas contra Portugal. Revoltados, os
Guarani enfrentaram as tropas portuguesas e espanholas na chamada "Guerra Guaranítica" e foram derrotados em 1756. Nesse embate, os Guarani foram liderados pelo índio Sepé Tiaraju, morto em combate em 07 de fevereiro de 1756, na Batalha de Caiboaté, pelos exércitos coloniais luso-hispânicos.

6 A Redução de São Miguel Arcanjo, um dos Sete Povos das Missões, foi fundada pelo Padre Cristóvão de Mendonza, em 1632, na região do Tape (noroeste do atual Rio Grande do Sul). Devido aos ataques dos bandeirantes paulistas, a população mudou-se, em 1638, para a margem ocidental do Rio Uruguai. Em 1687, os padres jesuítas fundaram novamente São Miguel Arcanjo no local do atual sítio (FONSECA, 2011).

7 Os aldeamentos (reduções) implantados por religiosos da Companhia de Jesus tinham por objetivo a evangelização dos indígenas, em sua maioria da etnia guarani e, ao mesmo tempo, a garantia da manutenção do território, dentro de um processo cambiante de disputas entre as coroas ibéricas (BRUXEL, 1987), ou seja, visavam ocupar terras destinadas à Espanha pelo Tratado de Tordesilhas, bem como difundir a fé cristã, imbuída do espírito da Contrarreforma. As reduções reuniam edificações (igreja, moradias, colégio e oficinas), construídas com técnicas distintas, além de estâncias e ervais. Eram espaços em que se cultivava a agricultura, a pecuária (com o gado introduzido pelos jesuítas) $o$ artesanato e se propiciava o desenvolvimento da arquitetura e das artes, num sistema de trabalho cooperativo, agregando novas tecnologias às técnicas indígenas tradicionais. Algumas reduções chegaram a reunir 7.000 indígenas.

\section{Referências}

ALETEIA. Você sabe o que significam JHS e IHS? 2017. Disponível em: <https://catolicodigital.com.br> Acesso em: 29 out. 2019.

BAKHTIN, Mikhail. Estética da criação verbal. Introdução e tradução do russo Paulo Bezerra; 4. ed. São Paulo: Martins Fontes, 2003.

BAKHTIN, Mikhail; VOLOCHINOV, Valentin. Marxismo e filosofia da linguagem. 16 ed. São Paulo: Hucitec, 2014. 
BARROS, Diana Luz Pessoa de. Teoria semiótica do texto. São Paulo: Ática, 2001.

BIANCHINI, Ana Maria. Símbolo católico JHS. Conheça o significado. Disponível em: Disponível em: < http://www.anamariabianchini.com.br> Acesso em: 29 out. 2019.

BRUXEL, Arnaldo. Os trinta povos Guaranis. 2.ed. Porto Alegre: EST, Nova Dimensão, 1987.

FIORIN, José Luiz. Linguística e pedagogia da leitura. SCRIPTA, Belo Horizonte, v. 7, n. 14, p. 107-117, $1^{\circ}$ sem. 2004.

FIORIN, José Luiz. Introdução ao Pensamento de Bakhtin. São Paulo: Ática, 2006.

FIORIN, José Luiz. Elementos de análise do discurso. São Paulo: Contexto, 2016.

FLOCH, Jean Marie. Petites mythologie de l'oeil e de l'esprit. Hadès-Benjamins, 1985.

FONSECA, Bianca Trindade da. Missões Jesuíticas: Antecedentes históricos. Revista P@rtes. Mar. 2011. Disponível em: <www. partes.com.br/politica/missoesjesuiticas. asp>. Acesso em: 10 nov. 2019.

GOMES, Regina Souza. O Ensino da Leitura: Uma abordagem Semiótica. Linguagem em (Re)vista, Ano 1, n.1. Niterói, jul/dez. 2004. Disponível em: <http://www.filologia.org.br/ linguagememrevista/1/09.pdf $>$. Acesso em: 20 nov. 2019.

GREIMAS, Algirdas Julien. Sobre o sentido: ensaios semióticos. Petrópolis: Vozes, 1975.

GREIMAS, Algirdas Juline; COURTÉS, Joseph. Dicionário de semiótica. 2. ed. São Paulo: Contexto, 2012.

HISTÓRIA de São Miguel Arcanjo. Disponível em: <https://cruzterrasanta.com.br>. Acesso em: 10 nov. 2019.

INAF 2018. Instituto Paulo Montenegro. Inaf 2018 - Nova edição do Inaf não aponta avanços nos níveis de alfabetismo no Brasil. Disponível em: <https://ipm.org.br/relatorios $>$. Acesso em: 20 de jan. 2020.
KOCH, Ingedore Grünfeld Villaça. Linguística textual e ensino de português. In: TOLDO, Cláudia Stumpf (Org.). Questões de linguística. Passo Fundo: UPF, 2013. p. 41-56.

MARTINELLI, Henrique Zantedeschi et al. A engenharia dos tratados internacionais de divisão do território português e espanhol e repercussões na organização indígena. In: CADORE, William Widmar; JACOMELLI, Jussara (Orgs.). Obras de engenharia, cenários e leituras [recurso eletrônico]: as relações sociais e minorias na formação da sociedade brasileira e rio-grandense Frederico Westphalen: URI - Frederico Westphalen, 2017. Série Cenários e Leituras Sociológicas; v. 1. p.75-89.

ORIGEM da Cruz Missioneira. Portal das Missões. Disponível em: <http://www. portaldasmissoes.com.br/site/view/id/1471/ origem-da-cruz-missioneira.html> Acesso em: jan. 2019.

PÓRTICO. Dicionário Michaelis. Disponível em: <www.uol.com.br/michaelis > . Acesso em: 20 nov. 2019.

Pórtico de São Miguel das Missões Portal das Missões. Disponível em: <http://www. portaldasmissoes.com.br/site/view/id/1045/ portico-de-sao-miguel-das-missoes.html>. Acesso em: jan. 2019.

SEPÉ TIARAJU: Líder guarani o espírito gaúcho de liberdade. Portal das Missões. 2019. Disponível em: <http://www.portaldasmissoes.com.br/noticias/view/id/59/sepe-tiaraju:-lider-guarani-o-espirito-gaucho-de-l.html>. Acesso em: jan. 2020.

TEIXEIRA, Lucia. Entre dispersão e acúmulo: para uma metodologia de análise de textos sincréticos. Caderno de discussão do Centro de Pesquisas Sociossemióticas. São Paulo. CPS/PUC-SP, 2003. p. 1-22

TEIXEIRA, Lucia. Para uma metodologia de análise de textos verbovisuais. In: TEIXEIRA, Lucia; OLIVEIRA, Ana Claudia de (Orgs.). Linguagens na comunicação: desenvolvimentos de semiótica sincrética. São Paulo: Estação das Letras e Cores, 2009. 